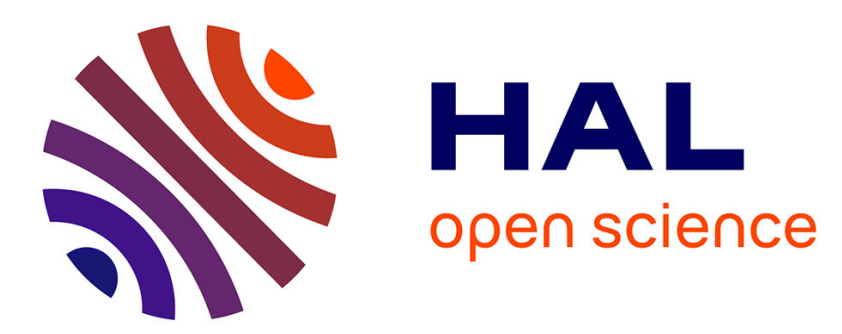

\title{
Metamodel Assisted Evolutionary Algorithm for Multi-objective Optimization of Non-steady Metal Forming Problems
}

\author{
Mohsen Ejday, Lionel Fourment
}

\section{- To cite this version:}

Mohsen Ejday, Lionel Fourment. Metamodel Assisted Evolutionary Algorithm for Multi-objective Optimization of Non-steady Metal Forming Problems. 13th ESAFORM Conference on Material Forming, Apr 2010, Brescia, Italy. pp.Pages 5-8, 10.1007/s12289-010-0689-0 . hal-00851431

HAL Id: hal-00851431

https://hal-mines-paristech.archives-ouvertes.fr/hal-00851431

Submitted on 14 Aug 2013

HAL is a multi-disciplinary open access archive for the deposit and dissemination of scientific research documents, whether they are published or not. The documents may come from teaching and research institutions in France or abroad, or from public or private research centers.
L'archive ouverte pluridisciplinaire HAL, est destinée au dépôt et à la diffusion de documents scientifiques de niveau recherche, publiés ou non, émanant des établissements d'enseignement et de recherche français ou étrangers, des laboratoires publics ou privés. 


\title{
METAMODEL ASSISTED EVOLUTIONARY ALGORITHM FOR MULTI-OBJECTIVE OPTIMIZATION OF NON-STEADY METAL FORMING PROBLEMS
}

\author{
M.Ejday ${ }^{1}$, L. Fourment ${ }^{1^{*}}$ \\ ${ }^{1}$ Mines ParisTech - CEMEF (Centre for Material Forming), Sophia Antipolis, France
}

\begin{abstract}
Multi-objective optimization problems are considered in the field of non-steady metal forming processes, such as forging or wire drawing. The Pareto optimal front of the problem solution set is calculated by a Genetic Algorithm. In order to reduce the inherent computational cost of such algorithms, a surrogate model is developed and replaces the exact the function simulations. It is based on the Meshless Finite Difference Method and is coupled to the NSGA-II Evolutionary Multi-objective Optimization Algorithm, in a way that uses the merit function. This function offers the best way to select new evaluation points: it combines the exploitation of obtained results with the exploration of parameter space. The algorithm is evaluated on a wide range of analytical multi-objective optimization problems, showing the importance to update the metamodel along with the algorithm convergence. The application to metal forming multi-objective optimization problems show both the efficiency of the metamodel based algorithms and the type of practical information that can be derived from a multi-objective approach.
\end{abstract}

KEYWORDS: Multi-objective optimization, Metamodel Assisted Evolutionary Algorithm, Meshless Finite Difference Method, Genetic Algorithm, Forging, Wire drawing.

\section{INTRODUCTION}

Evolutionary Multi-Objective Algorithms (EMOAs) can be regarded as the best techniques for determining the Pareto Optimal Front (POF) - the set of optimal solutions - of Multi-Objective Optimization Problems (MOOPs), as they provide a good diversity of points on the calculated Pareto set, even for difficult problems. However, they generally require a very large number of function evaluations, which sometimes makes these strategies impracticable when these evaluation are quite time consuming, as it often occurs in the metal forming context. The number of evaluations can be significantly reduced by replacing most of exact calculations by fast surrogate functions. This constitutes the frame of Metamodel assisted EMOA (M-EMOA), which is considered and studied in this paper, for a range of nonsteady metal forming applications. The Multi-Objective Optimization Problem is presented in section 2, the metamodel in section 3, and the coupling between the metamodel and NSGA-II [1] in section 4. Section 5 allows assessing the proposed approach through a number of academic test problem, while real world metal forming applications are presented in section 6 .

\section{MULTI-OBJECTIVE OPTIMIZATION PROBLEM (MOOP)}

A Multi-Objective Optimization Problem (1) can be defined as the search for the best set of solutions $X=\left(x_{1}, x_{2}, \ldots, x_{n}\right)^{T} \quad$ (where $n$ is the number of optimization parameters) that minimizes a number of $M$ conflicting (or not) objective functions and that satisfies a number of constraints which constitute the decision space $S$. Two goals are simultaneously followed: to find solutions that as close as possible to the POF and that are diverse enough to represent the front, as well as possible.

$\begin{array}{lll}\text { Minimize/Maximize } & \phi_{m}(X) & m=1, \ldots, M \\ & g_{j}(X) \geq 0 & j=1, \ldots, J \\ \text { subject to } & h_{k}(X)=0 & k=1, \ldots, K \\ & x_{i}^{L} \leq x_{i} \leq x_{i}^{U} & i=1, \ldots, n\end{array}$

\section{METAMODEL}

Literature suggests many metamodelling techniques to approximate expensive functions out of the knowledge of these functions values at a limited number of master points. Kriging [2] and Response Surface methodologies [4] are often used, as well as the Moving Least Square approach [7]. A variant of this latter is selected here: the Meshless Finite Difference Method (MFDM) [5]. In

\footnotetext{
* Corresponding author: Lionel Fourment, Mines ParisTech - CEMEF, B.P. 207, 06904 Sophia Antipolis Cedex, France, + 33493 9575 95, lionel.fourment@mines-paristech.fr
} 
order to compute $\phi\left(X_{i}\right)=\phi_{i}$, the value of $\phi$ at any point $X_{i}$ of the parameter space, the Liszka-Orkisz interpolation [6] consists in writing a second order Taylor's series expansions in the neighbouring of $X_{i}$, at any of the $\psi$ master points $X_{j}$, where $\phi\left(X_{j}\right)=\phi_{j}$ is known:

$$
\begin{aligned}
& \phi_{j}=a+\sum_{k=1}^{n} b_{k} x_{i j}^{k}+\frac{1}{2} \sum_{k, l=1}^{n} c_{k l} x_{i j}^{k} x_{i j}^{l}+O\left(\left\|\Delta_{i j}\right\|^{3}\right) \\
& a=\phi_{i}, \Delta_{i j}=X_{j}-X_{i}, \forall(k, l)=1, n: \\
& \text { with: } x_{i j}^{k}=x_{j}^{k}-x_{i}^{k}, b_{k}=\left(\nabla \phi_{i}\right)_{k}, c_{k l}=\left(\nabla^{2} \phi_{i}\right)_{k l}
\end{aligned}
$$

The $(a, b, c)$ solution minimizes the quadratic sum, $E(a, b, c)$ (4), of the $\psi$ Taylor's series expansions errors that can be written for all the available master points:

$$
\begin{gathered}
E(a, \boldsymbol{b}, \boldsymbol{c})= \\
\frac{1}{2} \sum_{j=1}^{\psi} w_{j}\left(a+\sum_{\lambda=1}^{n} b_{\lambda} x_{i j}^{\lambda}+\frac{1}{2} \sum_{\lambda, \mu=1}^{n} c_{\lambda \mu} x_{i j}^{\lambda} x_{i j}^{\mu}-\phi_{j}\right)^{2}
\end{gathered}
$$

where the weights $\omega_{j}=\left\|\Delta_{i j}\right\|^{-6}$ are naturally derived from the errors of the Taylor's expansions (2). It should be noticed that all master points are considered, contrary to the Moving Least Square Method [7] that requires defining or computing a specific radius value to exclude distant points. The minimization of $E(\boldsymbol{a}, \boldsymbol{b}, \boldsymbol{c})$ with respect to $(a, b, c)$ results into the resolution of the following linear system (5):

$$
A X=B
$$

$E(a, b, c)$, the quadratic sum Taylor's series expansions errors, provides an indication of the interpolation error $\Delta \tilde{\phi}_{i}$ of $\tilde{\phi}_{i}$ at point $\mathrm{i}$ :

$$
\Delta \tilde{\phi}_{i}=\sqrt{2\left(\sum_{j=1}^{\psi} w_{j}\right)^{-1} E(a, \boldsymbol{b}, \boldsymbol{c})}
$$

\section{METAMODEL ASSISTED NSGA-II}

In the proposed metamodel assisted NSGA-II, $M$ Updated, the initial metamodel $M_{0}$ is first constructed by $\psi$ master points provided by a Latin Hypercube Design Of Experiment [8]. It is utilized to approximate the function values for the individuals of the initial population $P_{0}$ of size $N$, generated by NSGA-II. At each new generation $t \leq N_{u}$ ( $N_{u}$ being the maximum number of generations), a $M_{t}$ metamodel is iteratively enriched into $M_{t+1}$ by adding $\theta$ new master points.
They are selected as the best $\theta$ first individuals of the $P_{t}$ population, which are sorted in growing rank by using the concept of domination [1] and decreasing crowding distance using the crowding distance criterion [1]. The sorting, specifically carried out for updating the metamodel, is based on the merit function $\tilde{\phi}-\Delta \tilde{\phi}$, contrary to the standard parts of the algorithm that use the surrogate function $\tilde{\phi}$, as also proposed in [1]. The new metamodel $M_{t+1}$ is then used to estimate the values of the $Q_{t}$ offspring population, as well as to update the estimations of the $P_{t}$ parent population. The prescribed number of generations, $N_{u}$, in such that new master points are regularly added at each generation:

$$
N_{u}=\frac{\psi_{\max }-\psi}{\theta}
$$

Where the maximum number of master points is chosen as: $\psi_{\max }=20 n$, the initial number of master points is given by: $\psi=1+n+n \frac{n+1}{2}$ and the number of added master points at each generation is $\theta=2^{M-1}$.

\section{ANALYTICAL TEST PROBLEMS}

M-Updated results are presented for two analytical problems, and are compared to those provided by NSGA-II by exactly computing the functions for all the individuals.

\subsection{CONSTRAINT PROBLEM: C-Min-Ex}

The C-Min-Ex problem is a two-objective constraint MOOP with two-variable proposed by Deb [1]. It is defined by (8).

Minimize $f_{1}\left(x_{1}, x_{2}\right)=x_{1} ; f_{2}\left(x_{1}, x_{2}\right)=\frac{1+x_{2}}{x_{1}}$

subjected to:

$$
\mid \begin{aligned}
& g_{1}\left(x_{1}, x_{2}\right)=x_{2}+9 x_{1} \geq 6 ; g_{2}\left(x_{1}, x_{2}\right)=-x_{2}+9 x_{1} \geq 1 \\
& 0.1 \leq x_{1} \leq 1 ; 0 \leq x_{2} \leq 5
\end{aligned}
$$

Table 1: Parameterisation of M-Updated for C-Min-Ex

\begin{tabular}{lcccccc}
\hline Algorithms & $N$ & $N_{g}$ & $N_{u}$ & $\lambda$ & $\theta$ & $\psi_{\max }$ \\
\hline NSGA-II & 100 & 50 & & & & \\
M-Updated & 100 & 50 & 17 & 6 & 2 & 40 \\
\hline
\end{tabular}

Figure 1 shows that, with only 40 exact evaluations, MUpdated is not only able to take into account the problem implicit constraints but also to find solutions that are close to those gives by NSGA-II with 5,500 evaluations. 


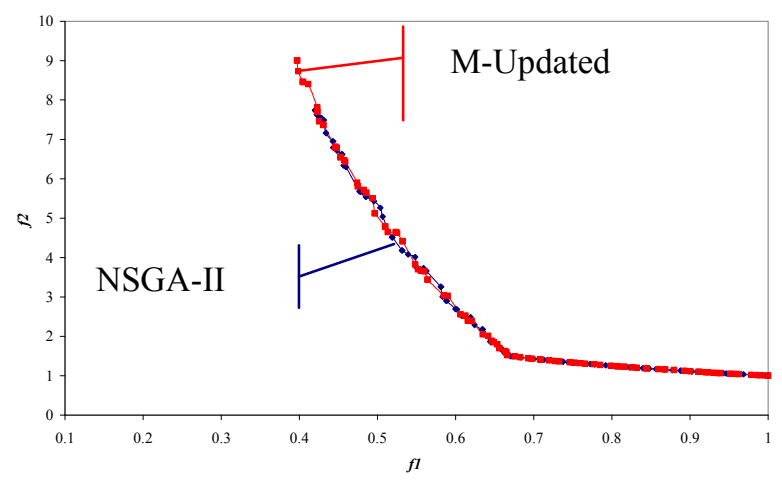

Figure 1: Comparison of the Pareto optimal front of $C$ Min-Ex obtained by M-Updated and NSGA-II

\subsection{TEST PROBLEM : KUR}

This two-objective optimization problem is complex with non-convex and disconnected Pareto optimal set (Figure 3) separated into 3 distinct regions (Figure 2). With 600 exact function evaluations M-Updated shows its efficiency by finding quite good results, close to those obtained by NSGA-II within 40,400 evaluations.

$$
\left\{\begin{array}{l}
\text { Minimize } f_{1}(X)=\sum_{i=1}^{2}\left[-10 \exp \left(-0.2 \sqrt{x_{i}^{2}+x_{i+1}^{2}}\right)\right] \\
\text { Minimize } f_{2}(X)=\sum_{i=1}^{3}\left[\left|x_{i}\right|^{0.8}+5 \sin \left(x_{i}^{3}\right)\right] \\
-5 \leq x_{i} \leq 5, \quad i=1,2,3
\end{array}\right.
$$

Table 2: Parameterisation of $M-U p d a t e d$ for $K U R$

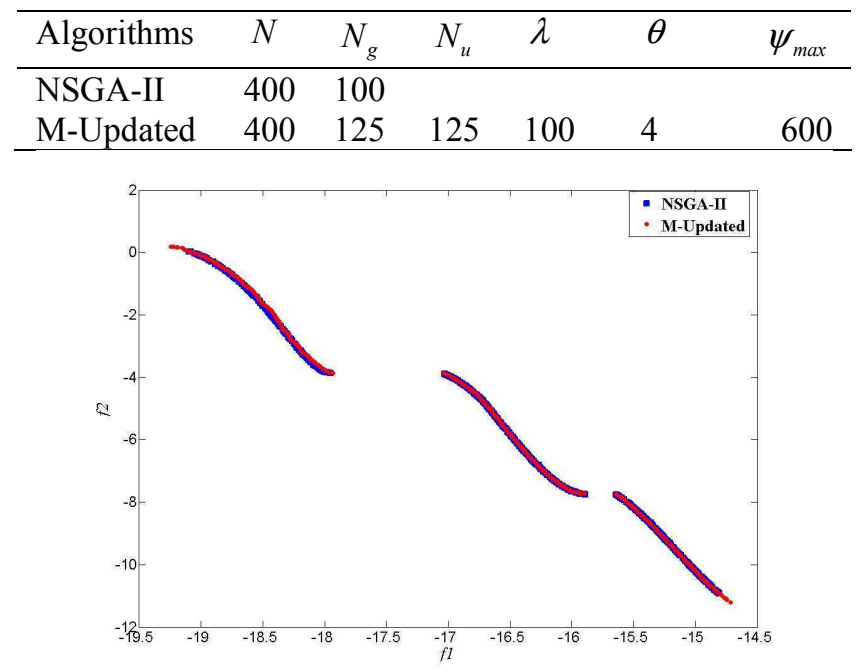

Figure 2: Comparison of the Pareto optimal fronts of KUR test problem obtained by M-Updated and NSGA-II

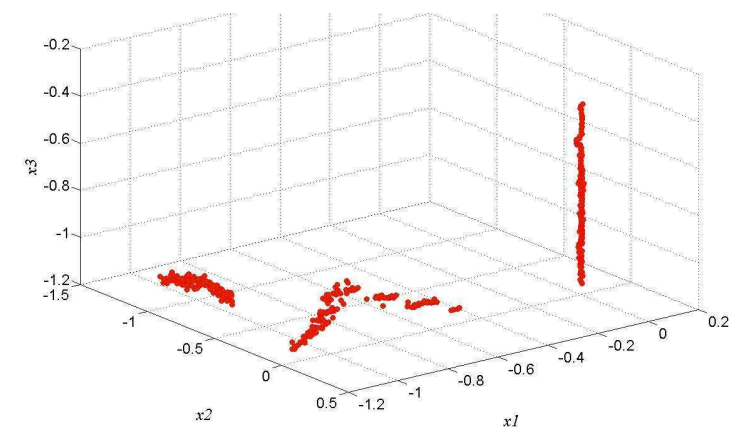

Figure 3: Pareto optimal solutions in the decision variable space for the test problem KUR

\section{METAL FORMING PROBLEMS}

\subsection{FORGING A CONNECTING ROD}

This first metal forming application regards the preform shape optimization of a cylindrical billet (see Figure 4) in order to forge a connecting rod (see final shape in Figure 5). The mono-objective optimization problem (9) consists in finding the best homothetic ratio, $x$, of the shape presented in Figure 4, in order to minimize the component mass while preserving proper filling of finishing dies at the end of forging (see Figure 5) - in other words, to minimize the flash volume while obtaining the right shape of the component. The constraint is aggregated into the objective function via a penalty approach:

$$
\left\{\begin{array}{c}
\text { Minimize } \quad \phi(x)=\text { volume }+ \text { filling } \\
0.8<x<1.05
\end{array}\right.
$$

The results obtained with 20 master points with both MUpdated and MAES are compared in Table 3; MAES is a Kriging based Metamodel Assisted Evolutionary Algorithm developed by M. Emmerich et al [3] that serves here as reference. M-Updated provides as good and even slightly better results than MAES for such a mono-objective problem.

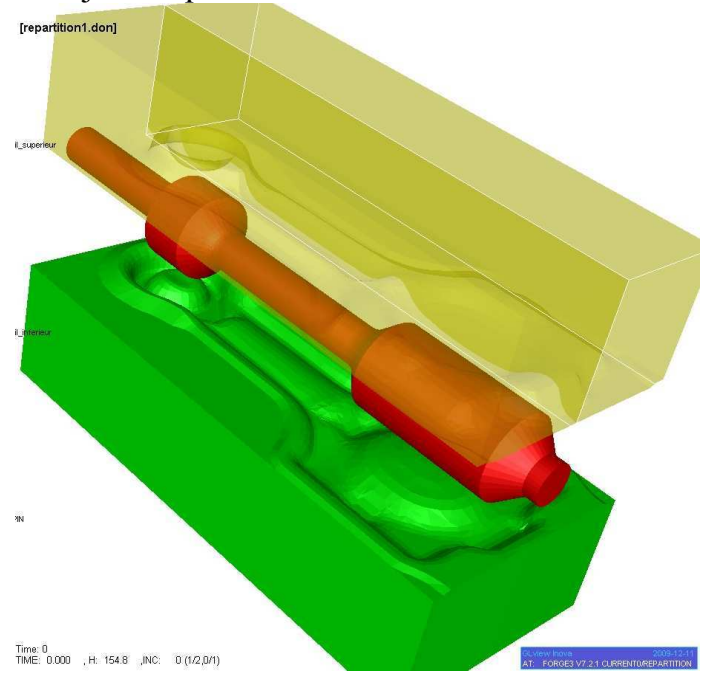

Figure 4: Initial preform and forging dies. 
Table 3: Results obtained by M-Updated and MAES

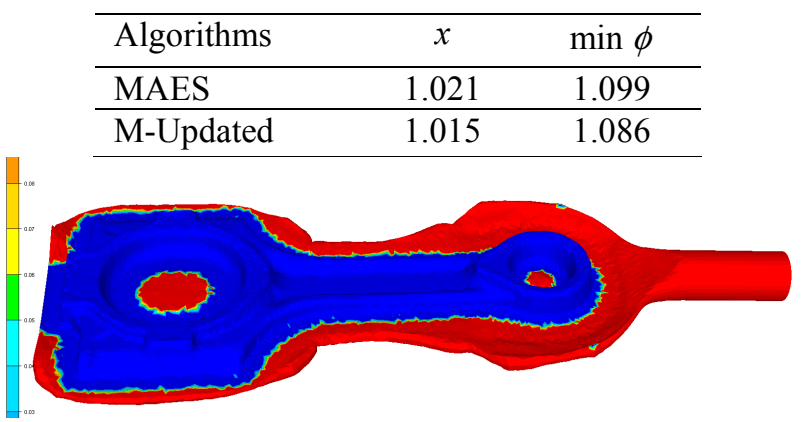

Figure 5: Isovalues of distance between the part and the dies at the end of forging (blue/drak $\rightarrow$ proper filling).

\subsection{WIRE DRAWING}

Two objectives are considered in the following wire drawing optimization problem (see Figure 7 and equation (10)): the usual minimization of the maximum drawing force, $F_{\max }$, and the less common minimization of the material damage, $D_{\max }$ There are two design variables, the entrance die semi-angle, $\alpha$, and the land length, $L$, (see Figure 7).

$$
: \begin{cases}\text { Minimize } & f_{1}(\alpha, L)=D_{\max } \\ \text { Minimize } & f_{2}(\alpha, L)=F_{\max } \\ & 0.1<\alpha, L<2\end{cases}
$$

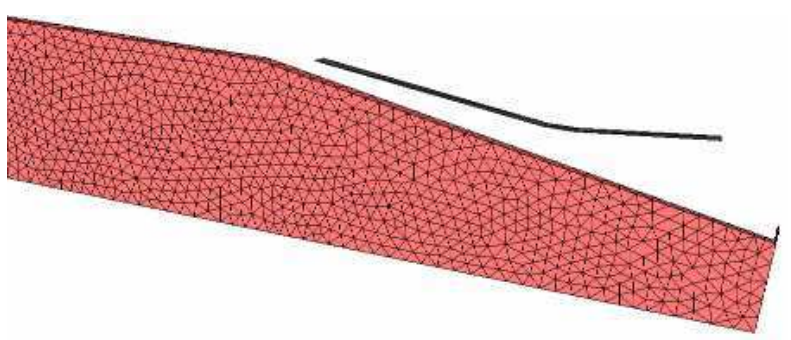

Figure 6: Simulation of the wire drawing process.

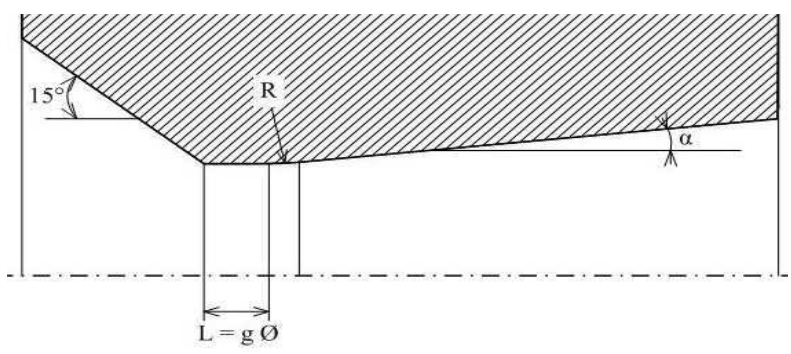

Figure 7: Drawing die geometry and definition of the optimization parameters.

Figure 8 shows the POF obtained with the M-Updated algorithm after 40 exact problem simulations. It can be noticed that: (a) the two objectives $F_{\max }$ and $D_{\max }$ are conflicting, (b) the POF is well represented with few calculations, (c) in a single optimization run, the POF allows getting a wide range of optimal solutions. The usually selected solution corresponds to the minimum force (right end of Figure 8), but the POF shows that by accepting a $3 \%$ increase of $F_{\max }$ it is possible to get a $45 \%$ decrease of the material damage $D_{\max }$.

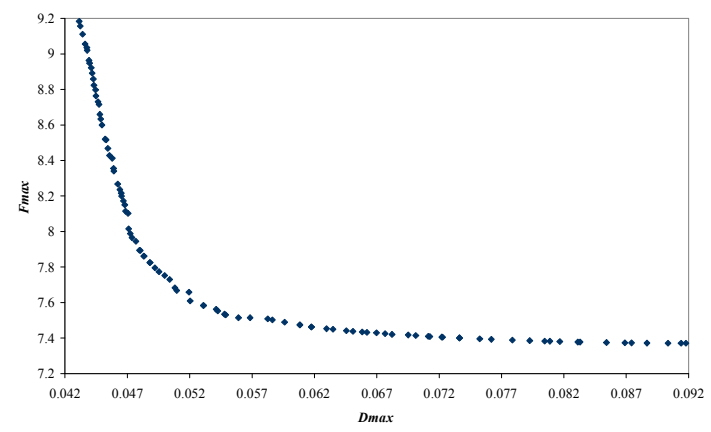

Figure 8: POF of the wire drawing process

\section{ACKNOWLEDGEMENT}

This work has been carried out in the frame of the LOGIC ANR program, which support is gratefully acknowledged. The contributions of Stéphane Marie, Thomas Massé and Pierre Montmitonnet in the design of the optimization cases is also gratefully acknowledged.

\section{REFERENCES}

[1] K. Deb. Multi-Objective Optimisation using Evolutionary Algorithms. John Wiley \& Sons Chichester, 2001.

[2] M. Emmerich, B. Naujoks, Metamodel-Assisted Multiobjective Optimization with Implicit Constraints and its Application in Airfoil Design, International Conference \& Advanced Course ERCOFTAC, Athens, Greece, 2004

[3] M. Emmerich, A. Giotis, M. Özdemir, T. Bäck, K. Giannakoglou. Metamodel-assisted evolution strategies, Int. Conf. on parallel problem solving from nature Springer, Berlin, GERMANY, 2002

[4] G. Ingarao, R. D. Lorenzo and F. Micari. Internal pressure and counter-punch action design in $\mathrm{Y}$ shaped tube hydroforming processes: A multiobjective optimisation approach, Computers and Structures 87 (2009) 591-602

[5] J. Krok, An Extended Approach to Error Control in Experimental and Numerical Data Smoothing and Evaluation Using the Meshless FDM, Meshfree Computational Mechanics 11 (2002) 913-945.

[6] T. Liszka, J. Orkisz, The finite difference method at arbitrary irregular grids and its application in applied mechanics, Comp. \& Struct. 11 (1980) 8395.

[7] P. Breitkopf, H. Naceur, A. Rassineux, P. Villon. Moving Least squares response surface approximation: Formulation and metal forming applications, Comp. \& Struct. 83 (2005) 1411-1428.

[8] S. J. Bates, J. Sienz, D. S. Langley, Formulation of the Audze-Eglais Uniform Latin Hypercube design of experiments, Advances in Engineering Software 34 (2003) 493-506. 